\title{
Pediatricians' perceptions of clinical practice guidelines
}

This article was published in the following Dove Press journal:

Journal of Multidisciplinary Healthcare

6 August 2014

Number of times this article has been viewed

\section{Mohamed A Hendaus \\ Ahmed H Alhammadi \\ Eshraga A Razig \\ Lulwa Alnaimi}

General Pediatrics Division, Department of Pediatrics, Hamad Medical Corporation, Doha, Qatar
Correspondence: Mohamed A Hendaus General Pediatrics Division, Department of Pediatrics, Hamad Medical Corporation, PO Box 3050, Doha, Qatar 3050

Tel +974 44392239

Fax +974 4443 957।

Emailmhendaus@yahoo.com
Background: Clinical practice guidelines (CPGs) are propositions for health care providers about the care of patients and are usually described as "systematically developed statements to assist practitioners' and patients' decisions about appropriate health care for specific circumstances".

Objectives: The purpose of this study was to investigate pediatricians' perceptions of clinical practice guidelines at Hamad Medical Corporation (HMC) in Qatar.

Methods: A cross-sectional study was conducted at HMC between May 1 and August 31, 2013 using a self-administered questionnaire that was distributed to 240 pediatricians.

Results: A total of 169/240 questionnaires were completed for a response rate of $70.4 \%$. Our main finding was that pediatricians at all levels are familiar with CPGs and use them. In addition, our doctors believe that CPGs lead to good quality of care, are practical, provide standardized patient care, will keep them up-to-date, decrease the rate of litigation, are evidence-based, do not restrict continuity of self-education, do not alter physician esteem, lead to improvement of outcome, and are practical. However, barriers that might impede pediatricians' use of CPGs are that CPGs affect their clinical judgment, do not match with their practice style, and do not reduce health care costs.

Conclusions: Pediatricians at HMC have positive perceptions of CPGs. The results of our study suggest that CPGs are likely to be implemented if more counseling and education are provided to pediatricians regarding the usefulness of evidence-based guidelines. In addition, a program should be initialized to remove barriers while simultaneously addressing physicians' concerns.

Keywords: clinical practice guidelines, pediatrics, perception

\section{Introduction}

Clinical practice guidelines (CPGs) are propositions for health care providers about the care of patients with categorical conditions. They should be predicated upon the best feasible research evidence and practice experience. ${ }^{1}$ They are usually described as "systematically developed statements to assist practitioners and patients' decisions about appropriate health care for specific circumstances". 2,3

The aim of CPG is to improve the safety and quality of patient care by providing clinicians with graded guidance predicated on evidence of best practice. ${ }^{4}$ Health care providers might deviate from implementing CPGs due to barriers such as receptiveness of guidelines, incentives to adhere to guidelines, and perceived effect of guidelines on patient outcomes. ${ }^{3}$ 


\section{Aims and objectives}

The objective behind conducting this survey study was to explore the pediatricians' perceptions towards clinical practice guidelines at Hamad Medical Corporation (HMC) in Qatar.

\section{Materials and methods Study design, period, setting, and participants}

A cross-sectional survey of physicians at Hamad Medical Corporation, the only tertiary care, academic and teaching hospital in the state of Qatar, was conducted between May 1, 2013 and August 31, 2013. A total of 244 physicians were targeted. In all, 240 eligible physicians were included in the survey. The four physicians conducting this study were excluded. In our health system, a specialist is a practicing physician who recently finished his/her residency program. A specialist will eventually be promoted to consultant if he or she meets the institution criteria for promotion. The pediatric physicians in our institution practice in the pediatric emergency center (PEC), general wards, subspecialty wards, neonatal intensive care unit (NICU), or pediatric intensive care unit.

\section{Survey instrument}

A self-administered questionnaire was distributed in the different pediatric departments to different levels and positions. Questionnaires were distributed on-site during working hours, and participants were asked to respond immediately. Some of the participants returned the questionnaire to a specified box while others preferred to return them by hand. Each participant was asked to complete all sections of the questionnaire. There was no incentive for subjects to participate, and no reminders were supplied. The questionnaire content was based on previous surveys ${ }^{2,3}$ but adapted to Qatari's system and modified for the purposes of our study. The questionnaire was composed of two sections and a total of 16 items. These sections addressed physicians' knowledge and attitudes regarding use of clinical practice guidelines (CPGs) in patient health care management.

Answers to questions of physicians' awareness, knowledge, and attitudes regarding the significance of using CPGs were based on 5-point Likert-style graded response options, ranging from "strongly agreed" to "strongly disagreed" and "don't know". Verbal consent was obtained before administering the questionnaire, and participants were informed of why the information was being collected and how it would be used for effective patient care management.
Before the start of the interview, a statement was read to participants informing them that their participation was voluntary and confirmed that their answers are anonymous and confidential. Approval for the study was obtained from Hamad Medical Corporation-Ethics Committee (Ref\#13174/13).

\section{Statistical analysis}

Qualitative and quantitative data values were expressed as frequencies along with percentages and mean $\pm \mathrm{SD}$ and median and range. Descriptive statistics were used to summarize demographic and all other characteristics of the participants. Associations between two or more qualitative or categorical variables were assessed using chi-square test. For small cell frequencies, the chi-square test with continuity correction factor or Fisher's exact test was applied. Pictorial presentations of the key results were made using appropriate statistical graphs. A two-sided $P$ value $<0.05$ was considered to be statistically significant. All statistical analyses were done using statistical package SPSS, version 19.0 (IBM Corporation, Armonk, NY).

\section{Results}

Out of the 240 questionnaires distributed, 169 (70.4\%) were returned by the end of the study. The ratio of male to female was 1.8:1. Among the participants were 68 consultants (40.2\%), 47 specialists (27.8\%), 20 clinical fellows (11.8\%), and 34 residents $(20.1 \%)$. In terms of years of experience, $43(25.4 \%)$ had $<5$ years, $47(27.8 \%)$ had between 5 and 10 years, $33(19.5 \%)$ had between 11 and 16 years, and $46(27.2 \%)$ had more than 16 years. It was found that $94.6 \%$ of physicians were familiar with clinical practice guidelines (CPG), and $80 \%$ of them used clinical practice guidelines in their clinical practice and patient care. Details of participants' current position, department, and year of experiences, familiarity and use of clinical practice guidelines are given in Table 1.

Physicians were asked to make an assessment of their familiarity and use of clinical practice guidelines in their own department and hospital. As measured by the questionnaire, physician perception and awareness of CPGs varied in view of the various aspects included and covered in standard CPGs (Table 1); $98.8 \%$ and $94.1 \%$ of physicians responded strongly agreed and agreed, respectively, that CPGs lead to good quality of care and have practical significance for patient care management. In all, $96.4 \%$ of physicians strongly agreed or agreed that $\mathrm{CPGs}$ provide more standardized patient care and should be implemented effectively throughout various 
Table I Description of physicians' demographic information and their perceptions of use of clinical practice guidelines

\begin{tabular}{|c|c|c|}
\hline Variable & $\begin{array}{l}\text { Frequency } \\
\text { (n) }\end{array}$ & $\begin{array}{l}\text { Percentage } \\
\text { (\%) }\end{array}$ \\
\hline \multicolumn{3}{|l|}{ Sex } \\
\hline Male & 108 & 63.9 \\
\hline Female & 61 & 36.1 \\
\hline \multicolumn{3}{|l|}{ Position } \\
\hline Consultant & 68 & 40.3 \\
\hline Specialist & 47 & 27.8 \\
\hline Fellow & 20 & 11.8 \\
\hline Resident & 34 & 20.1 \\
\hline \multicolumn{3}{|l|}{ Department } \\
\hline General pediatrics & 57 & 33.7 \\
\hline Pediatric specialty & 45 & 26.6 \\
\hline Neonatal intensive care unit & 24 & 14.2 \\
\hline Pediatric emergency center & 35 & 25.7 \\
\hline Pediatric intensive care unit & 8 & 4.7 \\
\hline \multicolumn{3}{|l|}{ Years of experience } \\
\hline$<5$ years & 43 & 25.5 \\
\hline $5-10$ years & 47 & 27.8 \\
\hline $11-16$ years & 33 & 19.5 \\
\hline$>16$ years & 46 & 27.2 \\
\hline \multicolumn{3}{|c|}{ Familiarity with clinical practice guidelines* } \\
\hline Yes & 159 & 94.6 \\
\hline No & 9 & 5.4 \\
\hline \multicolumn{3}{|l|}{ Use of clinical practice guidelines* } \\
\hline Very common & 42 & 25.3 \\
\hline Common & 100 & 60.2 \\
\hline Rarely & 24 & 14.5 \\
\hline
\end{tabular}

Note: *Some responses were missing.

pediatric disciplines. It is interesting to note that more than $80 \%$ of physicians agreed that CPGs provide recent advancement in the area and that use of CPGs will keep physicians more up-to-date about diagnosis and effective management of patient care. Also, it is worth mentioning that more than $90 \%$ of physicians agreed that CPGs also reduce medicolegal responsibilities. In all, $62.9 \%$ of physicians agreed that use of CPGs might affect physicians' clinical judgment. More than $75 \%$ of physicians disagreed that CPGs do not match with their practice style, restrict continuity of self-education, and are not evidence-based.

Familiarity with CPGs was observed to be higher among pediatric intensive care unit and NICU physicians $(100 \%)$ compared with physicians in other divisions, such as general pediatrics, pediatric subspecialty, and PEC (91.1\% to $95.6 \%)$; however, the difference was not statistically significant $(P=0.845)$. Use of CPGs reported as very common was found to be higher in PEC $(n=15,44.1 \%)$ compared with other pediatric divisions such as NICU $(n=8,33.3 \%)$, pediatric subspecialty $(n=9,20 \%)$, general pediatrics $(n=9,16.4 \%)$, and PEC $(n=1,12.5)$, though the difference, again, was not statistically significant $(P=0.127)$ (Figure 1$)$.

The association between physicians' awareness and use of CPGs according to their respective positions are shown in Figure 2. Among consultant and specialist physicians, the familiarity and use of CPGs were observed to be higher compared with fellow and resident physicians; however, the difference was not statistically significant ( $P=0.347$ ).

We studied the association between years of experience and familiarity with and use of CPGs. Among physicians who had more than 16 years of experience, the percentage of familiarity with CPGs was observed to be higher ( $\mathrm{n}=46$, $100 \%)$ compared with those with $<5$ years $(n=38,90.5 \%)$, $5-10$ years $(\mathrm{n}=44,93.6 \%)$, and $11-16$ years of experience $(n=31,93.9 \%)$; however, the difference was not statistically significant $(P=0.488)$. A similar association was observed between years of experience and whether use of CPGs was reported as very common or common (Figure 3).

\section{Discussion}

Conceivable CPGs are established on a systematic review of credible studies and published research. The systematic review should include all relevant scientific studies. ${ }^{2}$ We

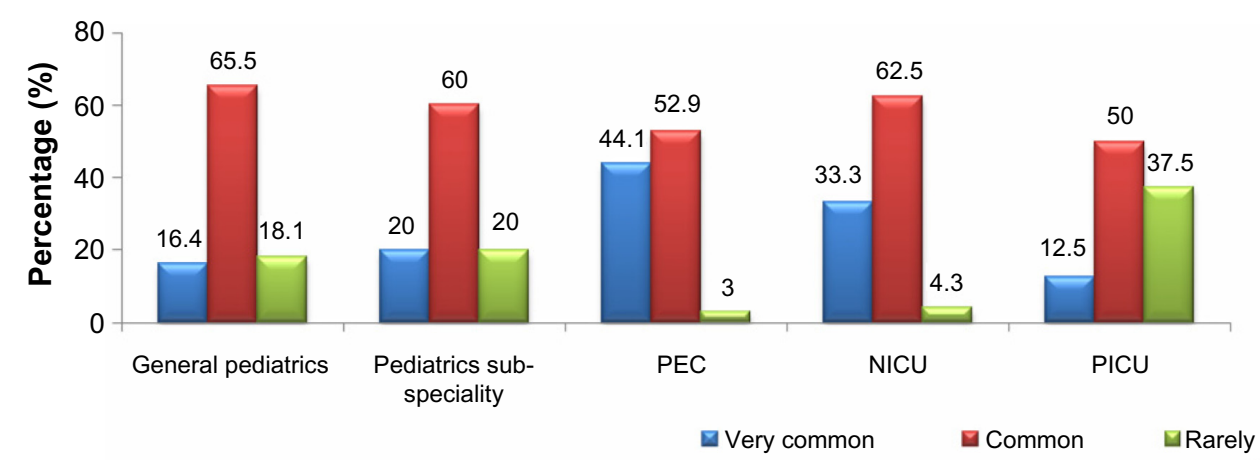

Figure I Use of clinical practice guidelines across departments.

Abbreviations: PEC, pediatric emergency center; NICU, neonatal intensive care unit; PICU, pediatric intensive care unit. 


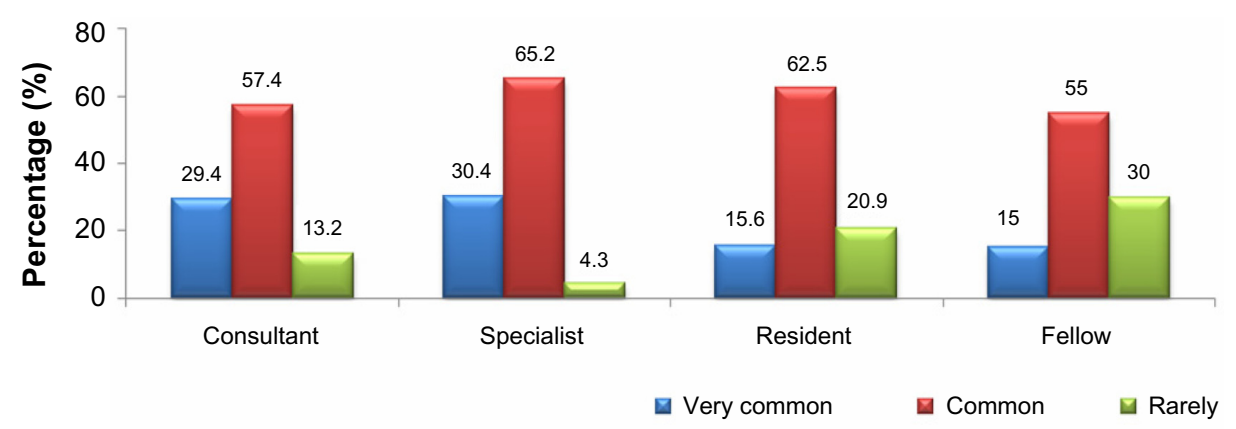

Figure 2 Use of clinical practice guidelines across position.

desired to study the perceptions of pediatricians toward CPGs using an anonymous questionnaire. There are only very few studies in the literature that touch our area of study.

Our main finding is that, contrary to expectation, the pediatricians questioned in our study at all levels are familiar with CPGs and use them. Our pediatricians have been trained in different countries, and they tend to apply what they learned during their residency years. Pediatric residents in our institution noticed the difference in practice among attending physicians, which was the reason that the concept of CPGs was introduced. In addition, our department is particular about the necessity of involving almost every physician when developing guidelines. For instance, when the urinary tract infection guideline was developed, general pediatricians as well as pediatric nephrologists were involved in the discussion. The same applies for other guidelines.

Our study showed that the urinary tract infection guideline is the most commonly used CPG, followed by guidelines concerning diabetic ketoacidosis, asthma exacerbation, and neonatal sepsis.

In addition, our doctors believe that CPGs lead to good quality of care, are practical, provide standardized patient care, will keep them up-to-date, decrease the rate of litigation, are evidence-based, do not restrict continuity of selfeducation, do not alter physician esteem, are descriptive, lead to improvement of outcome, and are practical. However, the barriers that might impede the use of CPGs are that they affect clinical judgment, do not match with our pediatricians' practice style, and do not reduce health care costs. Preceding adoption of CPGs, attitudes of physicians should be determined. ${ }^{2}$ In addition, physicians feel more comfortable with CPGs if they participate in their development. ${ }^{1}$

The response rate of our study $(70.4 \%)$ was higher than $56.5 \%$ as reported by Wahabi et al, ${ }^{2}$ and $49 \%$ as reported by Heselmans et al. ${ }^{5}$ Almost $95 \%$ of our pediatricians are familiar with clinical practice guidelines (CPGs), and $80 \%$ of them use clinical practice guidelines in their clinical practice and patient care, compared with $35 \%$ of physicians in the study conducted by Flores et al. ${ }^{6}$ The high rate of familiarity and use among our pediatricians, which is higher than other studies, ${ }^{2,5,6}$ might mean that physicians' negative attitudes toward CPGs in general will not be a future obstacle to implementation of CPGs in our institution.

Junior physicians are known to have positive attitudes toward CPGs, and they report higher adherence rates. ${ }^{3}$

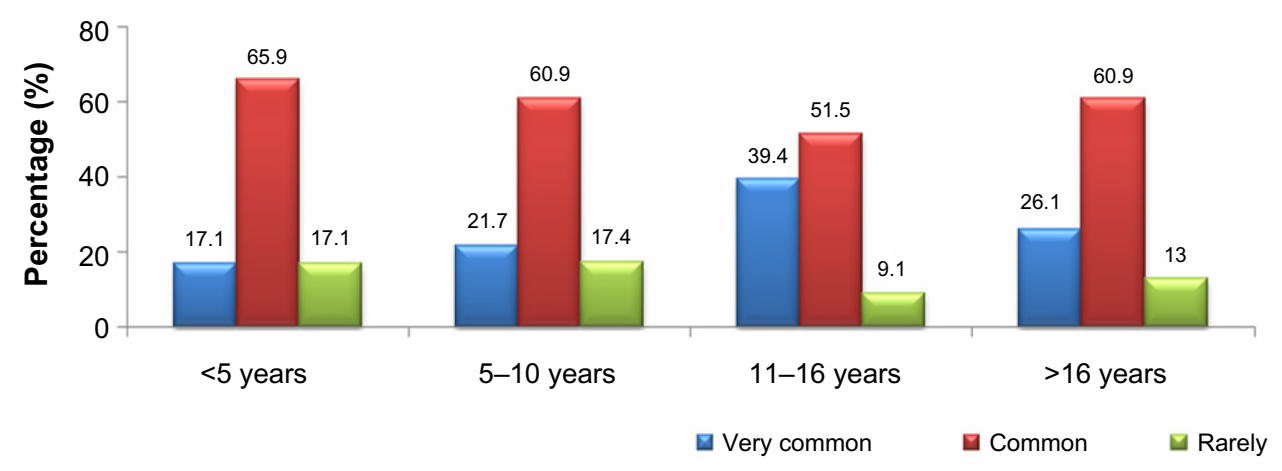

Figure 3 Use of clinical practice guidelines across years of experience. 
However, our study showed the opposite, which could be due to the fact that the majority of our senior physicians have prior experience in Western countries where CPGs are commonly used. In the United States, CPGs apparently played a role in proving negligence from the part of the physician. ${ }^{7}$ However, that is not what our pediatricians perceive. The reason could possibly be due to our setting being an inpatient setting, and more time is allotted for communication with families. One main concern is health care costs. There is insufficient support in the literature that introducing CPGs reduces health care costs. ${ }^{8}$ Our pediatricians' responses reflect this in that only $43 \%$ believe that CPGs reduce health care costs. A study conducted by Farquhar et $\mathrm{al}^{8}$ showed that $71 \%$ of clinicians consider CPGs to be good educational tools compared with $82 \%$ of our physicians, who consider that guidelines will keep them up-to-date.

An Australian study showed that $85 \%$ of physicians believe that CPGs are "developed by experts who don't understand general practice", and hence lack credibility. ${ }^{9}$

Our study participants opposed that sentiment, and three quarters of the pediatricians stated that CPGs are evidencebased. CPGs are being described by many practitioners as oversimplified and biased and that they defy physicians' autonomy and alter in a negative way doctor satisfaction. ${ }^{8}$ Outcome expectancy is the prediction that a certain act will lead to a specific repercussion. Health care providers will not adhere to certain guidelines if they believe that such guidance will not lead to outcome improvement. ${ }^{10}$ Almost $80 \%$ of our pediatricians disagreed or strongly disagreed that CPGs will unlikely lead to improvement of outcome. Clinicians are more likely to adhere to CPGs if they are derived from credible sources or organizations, ${ }^{8,11}$ if they are perceived as beneficial for patients, ${ }^{12}$ and if resources are available. ${ }^{13}$

\section{Limitations}

The strength of our study is that $70 \%$ of potential respondents returned the survey and hence the results reflect the actual experiences of pediatricians within the organization. A limitation could be that private hospitals were not included in the study and hence the results cannot be extrapolated to a state level.

\section{Conclusion}

Pediatricians at HMC have positive perception toward CPGs in general, which could positively influence the future implementation of evidence-predicated CPGs. The results of our study suggest that CPGs are likely to be implemented if more counsel- ing and education are provided to pediatricians regarding the usefulness of evidence-based guidelines. In addition, a program should be instigated to remove barriers while simultaneously addressing physicians' concerns.

\section{Acknowledgment}

We extend our gratitude to Dr Prem Chandra from the Medical Research Center at Hamad Medical Corporation for his assistance in data analysis.

\section{Financial disclosure}

No funds were provided to conduct the study.

\section{Disclosure}

The authors report no conflicts of interest in this work.

\section{References}

1. Shekelle P, Fletcher RH. Clinical Practice Guidelines. UpToDate ${ }^{\circledR}$ [homepage on the Internet]. Woltrs Kluwer Health; 2013. Available from: http://www.uptodate.com/contents/clinical-practice-guidelines. Accessed December 23, 2013.

2. Wahabi HA, Alzeidan RA, Fayed AA, Esmaeil SA, Al Aseri ZA. Attitude and practice of the health care professionals towards the clinical practice guidelines in King Khalid University Hospital in Saudi Arabia. J Eval Clin Pract. 2011;17(4):763-767.

3. El-Solh AA, Alhajhusain A, Saliba RG, Drinka P. Physicians' attitudes toward guidelines for the treatment of hospitalized nursing homeacquired pneumonia. J Am Med Dir Assoc. 2011;12(4):270-276.

4. Hakkennes S, Dodd K. Guideline implementation in allied health professions: a systematic review of the literature. Qual Saf Health Care. 2008;17(4):296-300.

5. Heselmans A, Donceel P, Aertgeerts B, Van de Velde S, Ramaekers D. The attitude of Belgian social insurance physicians towards evidencebased practice and clinical practice guidelines. BMC Fam Pract. 2009;10:64

6. Flores G, Lee M, Bauchner H, Kastner B. Pediatricians' attitudes, beliefs, and practices regarding clinical practice guidelines: a national survey. Pediatrics. 2000;105(3 pt 1):496-501.

7. Brushwood DB. Clinical practice guidelines and the standard of care. Am J Health Syst Pharm. 2000;57:159-161.

8. Farquhar CM, Kofa EW, Slutsky JR. Clinicians' attitudes to clinical practice guidelines: a systematic review. Med J Aust. 2002;177(9):502-506.

9. Gupta L, Ward JE, Hayward RS. Clinical practice guidelines in general practice: a national survey of recall, attitudes and impact. Med J Aust. 1997;166:69-72.

10. Cabana MD, Rand CS, Powe NR, et al. Why don't physicians follow clinical practice guidelines? A framework for improvement. JAMA. 1999;282(15):1458-1465.

11. Powell-Cope GM, Luther S, Neugaard B, Vara J, Nelson A. Provider-perceived barriers and facilitators for ischaemic heart disease (IHD) guideline adherence. J Eval Clin Pract. 2004;10(2):227-239.

12. Cabana MD, Rand CS, Becher OJ, Rubin HR. Reasons for pediatrician nonadherence to asthma guidelines. Arch Pediatr Adolesc Med. 2001;155(9):1057-1062.

13. Ricart M, Lorente C, Diaz E, Kollef MH, Rello J. Nursing adherence with evidence-based guidelines for preventing ventilator-associated pneumonia. Crit Care Med. 2003;31(11):2693-2696. 


\section{Publish your work in this journal}

The Journal of Multidisciplinary Healthcare is an international, peerreviewed open-access journal that aims to represent and publish research in healthcare areas delivered by practitioners of different disciplines. This includes studies and reviews conducted by multidisciplinary teams as well as research which evaluates the results or conduct of such teams or

healthcare processes in general. The journal covers a wide range of areas and welcomes submission from practitioners at all levels, from all over the world. The manuscript management system is completely online and includes a very quick and fair peer-review system. Visit http://www.dovepress.com/testimonials.php to read real quotes from published authors.

Submit your manuscript here: http://www.dovepress.com/journal-of-multidisciplinary-healthcare-journal 